\title{
Seismic relocation, focal mechanism and crustal seismic anisotropy associated with the 2010 Yushu $M_{\mathrm{S}} 7.1$ earthquake and its aftershocks*
}

\author{
Bo Zhao ${ }^{1,2, \uparrow}$ Yutao $\mathrm{Shi}^{2,3}$ and Yuan $\mathrm{Gao}^{2}$ \\ ${ }^{1}$ China Earthquake Networks Center, Beijing 100045, China \\ ${ }^{2}$ Institute of Earthquake Science, China Earthquake Administration, Beijing 100036, China \\ ${ }^{3}$ Institute of Geophysics, China Earthquake Administration, Beijing 100081, China
}

\begin{abstract}
The 2010 Yushu $M_{\mathrm{S}} 7.1$ earthquake occurred in Ganzi-Yushu fault, which is the south boundary of Bayan Har block. In this study, by using double difference algorithm, the locations of mainshock $\left(33.13^{\circ} \mathrm{N}\right.$, $96.59^{\circ} \mathrm{E}$, focal depth $10.22 \mathrm{~km}$ ) and more than 600 aftershocks were obtained. The focal mechanisms of the mainshock and some aftershocks with $M_{\mathrm{S}}>3.5$ were estimated by jointly using broadband velocity waveforms from Global Seismic Network (GSN) and Qinghai Seismic Network as well. The focal mechanisms and relocation show that the strike of the fault plane is about $125^{\circ}$ (WNW-ESE), and the mainshock is left-laterally strikeslip. The parameters of shear-wave splitting were obtained at seismic stations of YUS and L6304 by systematic analysis method of shear-wave splitting (SAM) method. Based on the parameters of shear-wave splitting and focal mechanism, the characteristics of stress field in seismic source zone were analyzed. The directions of polarization at stations YUS and L6304 are different. It is concluded that after the mainshock and the $M_{\mathrm{S}} 6.3$ aftershock on April 14, the stress-field was changed.
\end{abstract}

Key words: Yushu earthquake; double difference algorithm; focal mechanism; shear-wave splitting; stress

CLC number: $\mathrm{P} 315.3^{+} 3 \quad$ Document code: A

\section{Introduction}

At 07:49 on April 14, 2010 (BTC), an earthquake of $M_{\mathrm{S}} 7.1$ occurred in Yushu county of Qinghai province, China. According to China Earthquake Networks Center $(\mathrm{CENC})$, the epicenter $\left(33.13^{\circ} \mathrm{N}, 96.59^{\circ} \mathrm{E}\right)$ is located in Ganzi-Yushu fault with focal depth of $14 \mathrm{~km}$. GanziYushu fault is the boundary between Bayan Har block and Qiangtang block and it is strongly active. After the mainshock, a large number of aftershocks occurred along the Ganzi-Yushu fault.

Double difference algorithm is adopted widely for relative locating of small earthquakes, which can lower the locating error. The difference in travel times

\footnotetext{
* Received 30 September 2011; accepted in revised form 12 December 2011; published 10 February 2012.

† Corresponding author. e-mail: zhaobo@seis.ac.cn

(C) The Seismological Society of China, Institute of Geophysics, China Earthquake Administration, and Springer-Verlag Berlin Heidelberg 2012
}

between two events observed at one station can be attributable to the spatial offset between the events with high accuracy (Waldhauser and Ellsworth, 2000). Using double difference technique can make inaccurate velocity model have a minimum impact on earthquake locating. After relocating, the distribution of aftershocks is closely related to geological structure (Zhao et al., 2011a; Yang and Chen, 2004; Zhu et al., 2005, 2008). Results of relocation can also determine the fault plane in focal mechanism solutions. In this study, double difference algorithm was used to relocate mainshock and aftershocks sequence for Yushu $M_{\mathrm{S}} 7.1$ earthquake.

As we have known, crustal anisotropy is a common phenomenon (Crampin and Chastin, 2003; Crampin and Peacock, 2005). When seismic wave travels in crust, the shear-wave split into two waves which have different velocities and approximately orthogonal polarizations character. In the crust, the splitting is caused by vertically aligned microcracks parallel to stress direc- 
tion (Crampin, 1994, 1999). Many studies showed that crustal anisotropy could indicate the characteristics of the regional stress field and tectonic features (Gao et al, 1995; Zhao et al., 2011b; Shi et al., 2009; Wu et al., 2007; Gao and Wu, 2008; Zhang et al., 2009). Shearwave splitting is related to the changes of stress and seismicity (Gao et al., 1998; Gao and Crampin, 2004, 2006; Zheng et al., 2008). As the origin times and spatial distribution of near-field small earthquakes can not be well constrained, shear-wave splitting is bound by the distribution of small earthquakes. So the accurate relocation of Yushu earthquake sequence not only is conducive to studying seismicity and fault feature, but also improves the accuracy of shear-wave splitting parameters (Zhao and Gao, 2010). Since the parallel vertical microcracks affect shear-wave splitting, which is controlled by in situ compressive stress, stress analysis could provide important hints to seismic anisotropy.

Precise locations of earthquakes are important to improve the accuracy of shear-wave splitting parameters and focal mechanism solutions. In addition, focal mechanism solutions and shear-wave splitting results could be compared with each other. In this study, we will analyze the impact of stress and geological structure on shear-wave splitting according to focal mechanisms, relocations, and characteristics of shear-wave splitting.

\section{Relocation of the aftershock se- quence}

YUS station is the only permanent seismic station near epicenter of $M_{\mathrm{S}} 7.1$ Yushu earthquake. When station is rare around earthquake sequence, the residuals of location become larger. In order to solve this problem, eight temporary seismic stations were installed by China Earthquake Administration and recorded more than 3000 aftershocks from April 14, 2010 to December 31,2010 , including one aftershock with $M_{\mathrm{S}} 6.3$, two aftershocks with $M \geq 5.0$ and more than 30 aftershocks with $M_{\mathrm{S}} 3.0$ (from CENC).

The data used in this study are from phase report (from CENC), in which there are more than 9700 $\mathrm{P}$-wave phase and more than $9600 \mathrm{~S}$-wave phase. Before temporary seismic stations were built, many small earthquakes have only single-station record, which can not be composed with other earthquake into "earthquake pairs". These single-station record events cannot be relocated by using HypoDD program. So the results with $M_{\mathrm{L}} 1.0-2.9$ are less.

Because most of aftershocks have only single- station (YUS) record, only 677 of totally recorded 1700 aftershocks were relocated using the double difference algorithm. The RMS residuals are reduced from $0.76 \mathrm{~s}$ to $0.12 \mathrm{~s}$. The result shows that aftershock sequence is along Ganzi-Yushu fault in WNW-ESE direction (Figure 1). The mainshock and aftershock with $M_{\mathrm{S}} 6.3$ are in the middle of the aftershock belt, and two aftershocks with $M_{\mathrm{S}} 5.3, M_{\mathrm{S}} 5.7$ are in the northwest of the belt. The parameters of some earthquakes are listed in Table 1.

Table 1 The parameters of mainshock and some aftershocks

\begin{tabular}{ccccccc}
\hline & \multicolumn{2}{c}{ Origin time } & Long. & $\begin{array}{c}\text { Lat. } \\
/{ }^{\circ} \mathrm{N}\end{array}$ & $\begin{array}{c}\text { Depth } \\
/ \mathrm{km}\end{array}$ & $M_{\mathrm{S}}$ \\
\cline { 2 - 5 } & $\begin{array}{c}\text { Date } \\
\text { a-mo-d }\end{array}$ & $\begin{array}{c}\text { Time } \\
\text { h:min:s }\end{array}$ & \multicolumn{1}{c}{$\mathrm{E}$} & & & \\
\hline 0 & $2011-04-14$ & $05: 39: 58$ & 96.59 & 33.11 & 15 & 4.8 \\
1 & $2010-04-14$ & $07: 49: 36$ & 96.59 & 33.13 & 10.22 & 7.1 \\
2 & $2010-04-14$ & $09: 25: 16$ & 96.58 & 33.19 & 16.22 & 6.3 \\
3 & $2010-04-17$ & $07: 04: 12$ & 96.51 & 33.18 & 10.03 & 3.6 \\
4 & $2010-04-29$ & $00: 48: 37$ & 96.52 & 33.19 & 9.03 & 4.6 \\
5 & $2010-05-29$ & $10: 29: 47$ & 96.19 & 33.32 & 9.03 & 5.7 \\
6 & $2010-06-03$ & $13: 35: 44$ & 96.22 & 33.34 & 11.59 & 5.3 \\
\hline
\end{tabular}

Note: The No. 0 earthquake is the foreshock. The location of the foreshock is not relocated in this paper and its location is from China Earthquake Networks Center.

In Figure 1a, it can be seen that the pattern of the epicentral distribution is clear and aftershocks concentrate along the Yushu fault. The seismic belt is along WNW-ESE. In Figures $1 \mathrm{~b}$ and 1c, the length of the seismic belt is about $120 \mathrm{~km}$, and its width is approximately $20 \mathrm{~km}$. Figure 1c shows that the aftershocks are vertical distribution. This study concluded that this seismogenic fault is a strike-slip with high tilt angle.

In Figure 2a, we can see that 91 percent of aftershocks drop in 5-15 km depth range before relocation. After relocation, the focal depth distribution of aftershocks is mainly in the scope from 0 to $20 \mathrm{~km}(95 \%$ totally). The average depth is $12.97 \mathrm{~km}$. The seismogenic layer of Yushu earthquake sequence is in the upper crust.

\section{Focal mechanism of $M_{\mathrm{S}} 7.1$ mainshock, a foreshock and some aftershocks}

In order to study more about the earthquake parameters, the focal mechanisms of the foreshock, mainshock and some aftershocks with $M_{\mathrm{S}}>3.5$ were estimated by the CPS program (Computer Programs in Seismology) (Herrmann, 2009) in this study. We used far-filed seismic wave data which was recorded by 

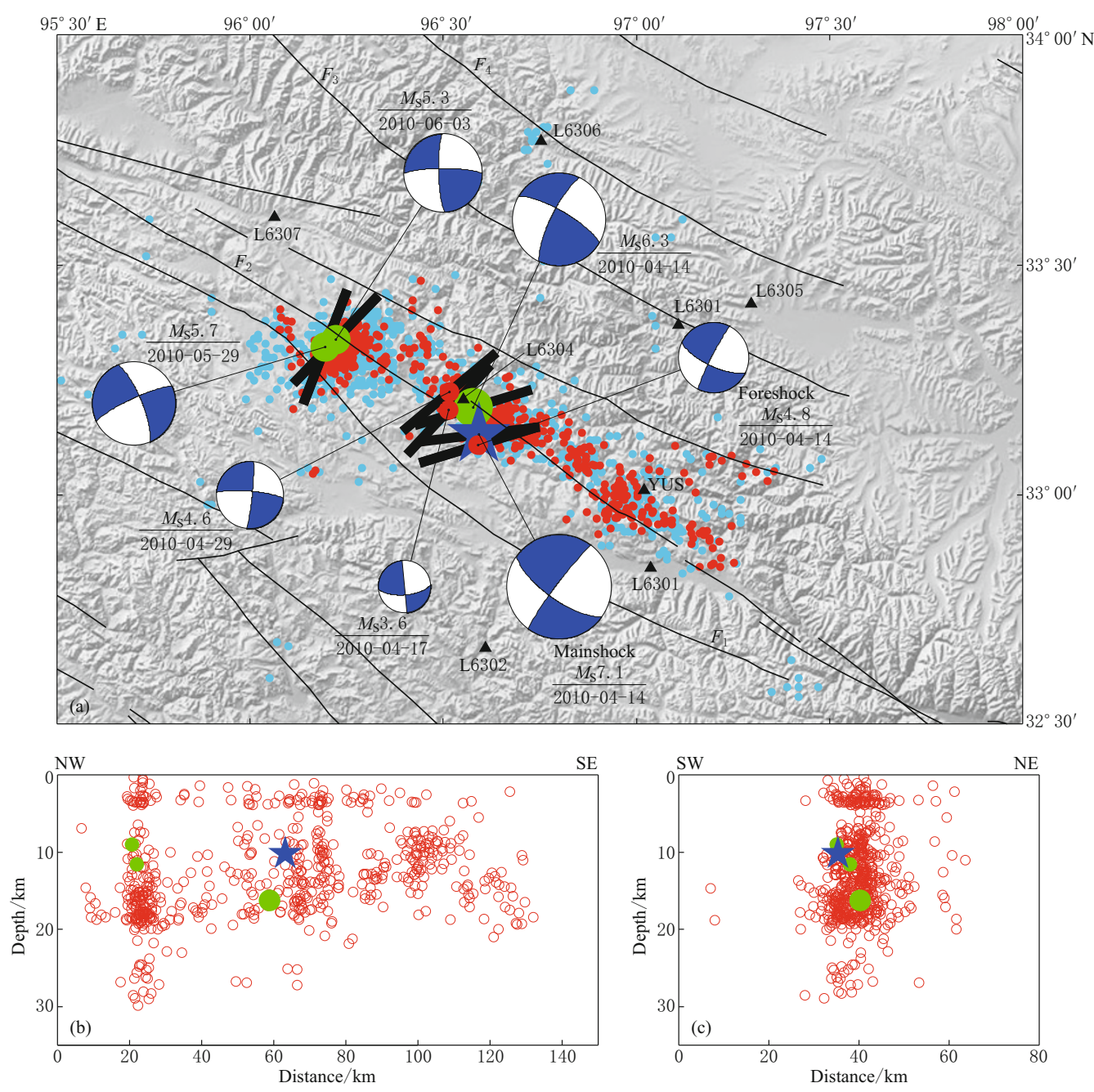

Figure 1 The relocation result of Yushu earthquake sequence. (a) Epicentral distribution of Yushu earthquake sequence. Focal mechanisms of several larger events are shown. (b) Focal depth distribution of earthquake sequence in the profile along main fault. (c) Focal depth distribution of earthquake sequence in the profile perpendicular to main fault. In figure, red circles are the epicenter of relocation results, blue circles are the epicenter before relocation. Small green solid circles represent aftershocks magnitude $M_{\mathrm{S}} 5.0-5.9$. Big green solid circles represent aftershock magnitude $M_{\mathrm{S}} 6.3$. Blue star is mainshock $M_{\mathrm{S}} 7.1$. The black bars represent the $P$ axes. Triangles represent seismic stations. $F_{1}$ is Zigasi-Deqin fault, $F_{2}$ is Ganzi-Yushu fault, $F_{3}$ is Chengduo-Qumalai-Wudaoliang fault, $F_{4}$ is Zayun-Chumaerhe fault.

Global Seismic Network (GSN) to invert focal mechanism of mainshock. The epicentral distance is within $30^{\circ}-90^{\circ}$. The distribution of GSN stations is shown in Figure 3a. We used AK135 velocity model to compute the Green's functions. The waveforms were rotated to vertical, radial, and transverse components and inspected for signal quality in $0.008-0.025 \mathrm{~Hz}$ pass-band. We used ground velocity records in order to reduce the influence of instrument noise on the deconvolution of the instrument response. By using the CPS program, we got the focal mechanism of mainshock. Nodal plane 1: strike $217^{\circ}$, dip $85^{\circ}$, slip $-160^{\circ}$; nodal plane 2 : strike $125^{\circ}$, dip $70^{\circ}$, slip $-5^{\circ} . M_{0}=1.51 \times 10^{26}, M_{\mathrm{W}}=6.7$. In Figure $3 \mathrm{~b}$, we compare observed trace with predicted trace.

Focal mechanisms of aftershocks were determined using waveforms from Qinghai Seismic Network. These waveforms are near-field data, and the time window is $10 \mathrm{~s}$ before $\mathrm{P}$ arrival and $180 \mathrm{~s}$ after $\mathrm{P}$ arrival. Waves are band-pass-filtered in velocity in $\mathrm{m} / \mathrm{s}$ with frequency 0.02 to $0.1 \mathrm{~Hz}$. All focal mechanism inversions were calculated with Computer Programs in Seismology package of Herrmann. 

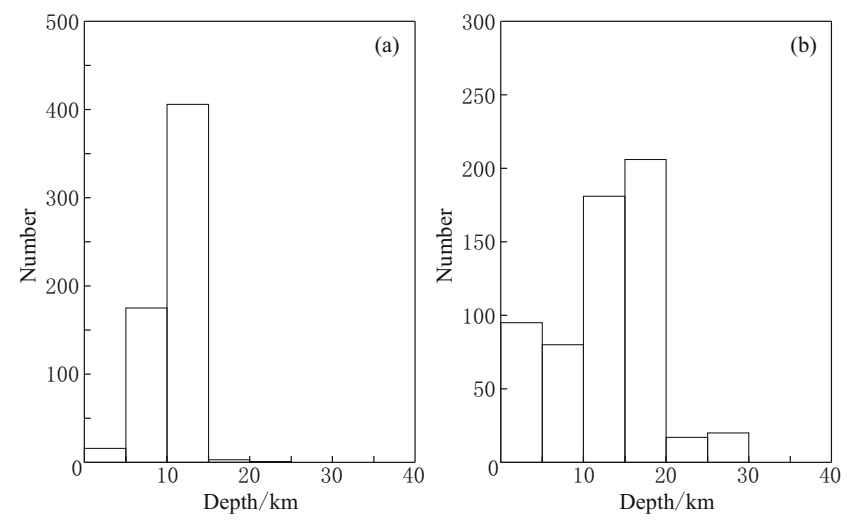

Figure 2 Statistical histogram of depth distribution before (a) and after (b) relocation.

Table 2 shows that the inclinations of $P$ axes and $T$ axes of the four earthquakes are small. Therefore, in fault region, horizontal force is bigger than the vertical force. Seismogenic fault rupture was caused by horizontal force, and the dip angle approximates $90^{\circ}$. Focal mechanism solutions are consistent with the results of double difference relocation. And according to the relocation, this study concluded that nodal plane $2\left(125^{\circ}\right.$, $70^{\circ},-5^{\circ}$ ) of the mainshock was the fault plane. The mainshock is left-laterally strike-slip type earthquake (Figure 1a).

The result of relocation shows that the epicenter of the $M_{\mathrm{S}} 7.1$ mainshock is close to the biggest aftershock with $M_{\mathrm{S}} 6.1$, and they both distribute in the middle of the seismic belt. Another two aftershocks with $M_{\mathrm{S}} 5.7$ and $M_{\mathrm{S}} 5.3$ are in the northwest of the belt. In Figure 1, the directions of the black bars represent the azimuth of the $P$ axes, and their degrees are shown in Table 3. $P$ axes of the foreshock, mainshock and aftershocks with $M_{\mathrm{S}} 6.7$ are near ENE, however, after more than a month, $P$ axes of aftershocks with $M_{\mathrm{S}} 5.7$ and $M_{\mathrm{S}} 5.3$ oriented to NNE. And after the mainshock, the $P$ axes of some small aftershocks with $3.5<M_{\mathrm{S}}<4.9$ which are near the mainshock, oriented to NNE. The difference between these orientation is approximate $45^{\circ}$.

Table 2 Focal mechanism of mainshock and some aftershocks

\begin{tabular}{|c|c|c|c|c|c|c|c|c|c|c|c|c|}
\hline \multirow{2}{*}{ No. } & \multicolumn{3}{|c|}{ Nodal plane 1} & \multicolumn{3}{|c|}{ Nodal plane 2} & \multicolumn{2}{|c|}{$P$ axis } & \multicolumn{2}{|c|}{$B$ axis } & \multicolumn{2}{|c|}{$T$ axis } \\
\hline & Strike/ ${ }^{\circ}$ & $\operatorname{Dip} /{ }^{\circ}$ & Rake $^{\circ}$ & Strike/ ${ }^{\circ}$ & $\operatorname{Dip} /{ }^{\circ}$ & Rake/ ${ }^{\circ}$ & $\mathrm{Az} /^{\circ}$ & $\mathrm{Pl} /^{\circ}$ & $\mathrm{Az} /^{\circ}$ & $\mathrm{Pl} /{ }^{\circ}$ & $\mathrm{Az} /{ }^{\circ}$ & $\mathrm{Pl} /{ }^{\circ}$ \\
\hline 0 & 207 & 85 & -160 & 115 & 70 & -5 & 73 & 17 & 219 & 69 & 339 & 11 \\
\hline 1 & 217 & 85 & -160 & 125 & 70 & -5 & 83 & 17 & 229 & 69 & 349 & 11 \\
\hline $1^{*}$ & 209 & 88 & -173 & 119 & 83 & -2 & 74 & 6 & 222 & 83 & 344 & 4 \\
\hline $1^{* *}$ & 210 & 77 & -180 & 120 & 90 & -13 & 74 & 9 & 300 & 77 & 166 & 9 \\
\hline 2 & 206 & 75 & 164 & 300 & 75 & 12 & 253 & 0 & 344 & 69 & 163 & 21 \\
\hline 3 & 6 & 85 & -170 & 275 & 80 & -5 & 230 & 11 & 32 & 79 & 140 & 4 \\
\hline 4 & 175 & 90 & -155 & 85 & 65 & 0 & 43 & 17 & 175 & 65 & 307 & 17 \\
\hline 5 & 245 & 80 & -15 & 338 & 75 & -170 & 201 & 18 & 32 & 72 & 292 & 3 \\
\hline 6 & 178 & 80 & 170 & 270 & 80 & 10 & 224 & 0 & 315 & 76 & 134 & 14 \\
\hline
\end{tabular}

Note: $1^{*}$ represents the result from Liu et al. (2010); $1^{* *}$ represents the result from Harvard Global Moment Tensor Solution (http://earthquake.usgs.gov/earthquakes/eqinthenews/2010/us2010vacp/neic_vacp_gcmt.php).

\section{Seismic anisotropy}

Using seismic records from Qinghai Seismic Network, we compute anisotropy characteristic parameters using seismic analysis method of shear-wave splitting. As the seismic stations near the source region are scarce, the depths of some aftershocks can not be relocated. As the average depth of the earthquake sequence is 12.97 $\mathrm{km}$, the seismic data with epicenter less than $13 \mathrm{~km}$ increase in the study. The reliability and effectiveness of this method have been proved (Shi et al., 2009).

SAM method was proposed based on the correlation function. It includes three steps in the calculation of cross-correlation function, which are separately elim- ination of time-delay, analysis of polarization, and constructing function of self-examination (Gao and Zheng, 1995; Gao et al., 2008).

By using SAM method, the parameters of shearwave splitting were obtained for YUS and L6304 seismic stations (Table 3). The direction of polarization of fast shear-wave is near NE in YUS station, and near NNE in L6304. The direction of polarization in YUS is different from that of Ganzi-Yushu fault. However, it is consistent with the direction of $P$ axes of foreshock, mainshock and $M_{\mathrm{S}} 6.3$ aftershock which occurred on April 14,2010 . The direction of polarization in L6304 is consistent with the $P$ axes of $M_{\mathrm{S}} 5.3$ and $M_{\mathrm{S}} 5.7$ aftershocks which occurred on May 29, and June 3, 2010 respectively. 


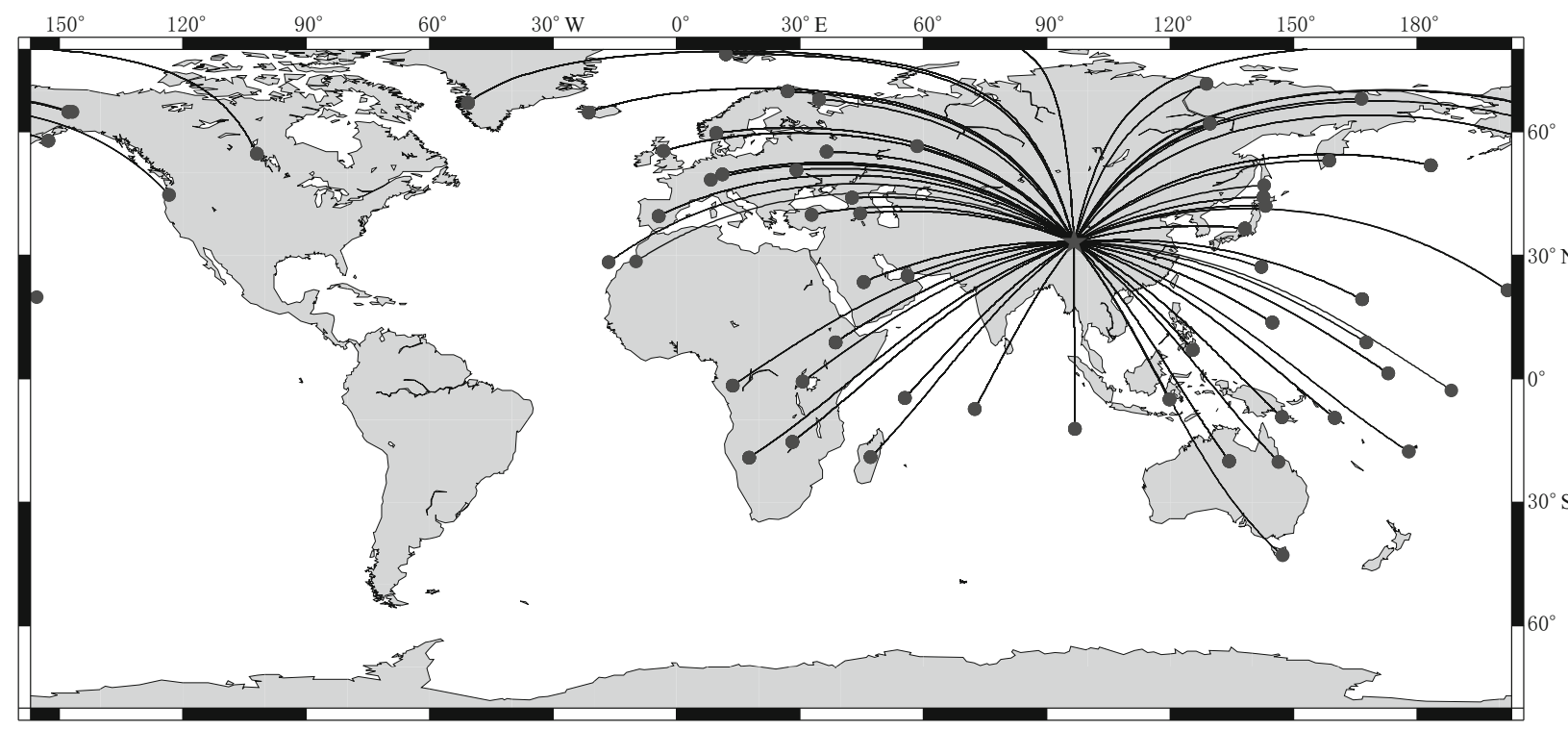

$\mathrm{P}-\mathrm{Z}$

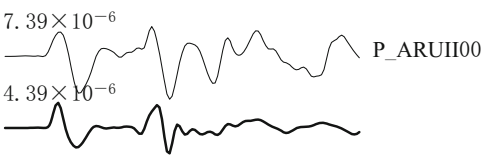

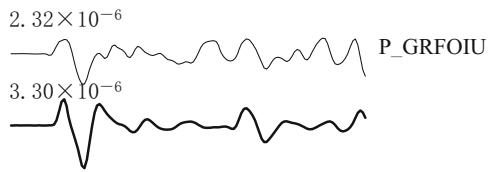

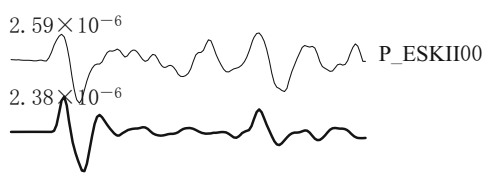

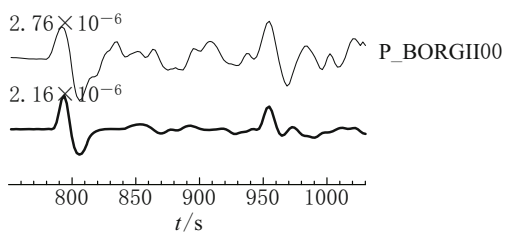

SV-R
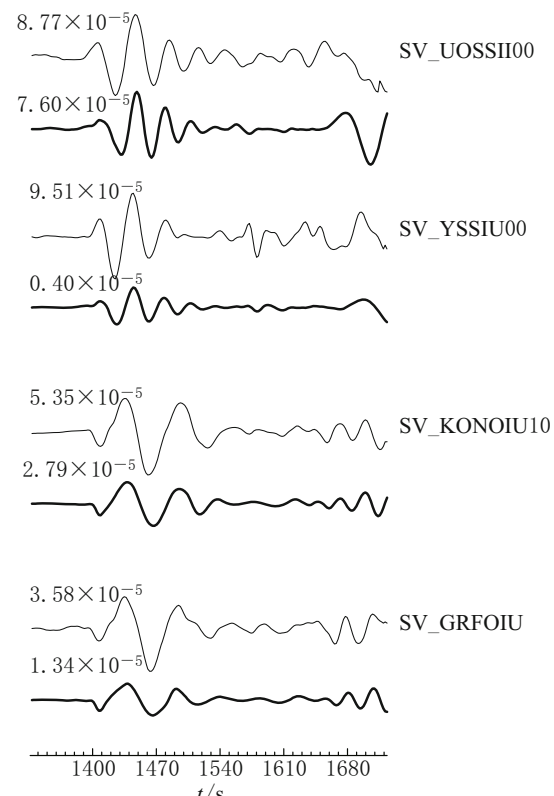

(b)
$\mathrm{SH}-\mathrm{T}$
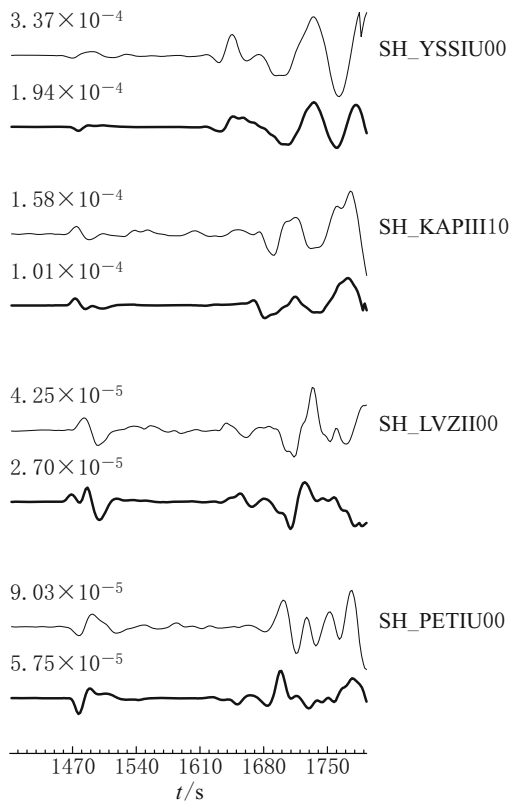

Figure 3 Distribution of seismic stations and example of the waveform fitting. In Figure 3a, block solid circles represent seismic stations (GSN/IRIS). In Figure 3b, the observed trace is shown in thin curve and the predicted trace in thick curve. The maximum amplitude in the time window is shown on the left of trace. Station name is shown on the right.

Table 3 Parameters of shear-wave splitting in Yushu source area

\begin{tabular}{cccccc}
\hline Station & Long. $/{ }^{\circ} \mathrm{E}$ & Lat. $/{ }^{\circ} \mathrm{N}$ & $\begin{array}{c}\text { Number of } \\
\text { records }\end{array}$ & $\begin{array}{c}\text { Average } \\
\text { polarization } /{ }^{\circ}\end{array}$ & Time delay/s \\
\hline YUS & 33.0 & 97.2 & 36 & $85 \pm 32$ & $0.021 \pm 0.013$ \\
L6304 & 33.2 & 96.6 & 13 & $19 \pm 17$ & $0.032 \pm 0.017$ \\
\hline
\end{tabular}



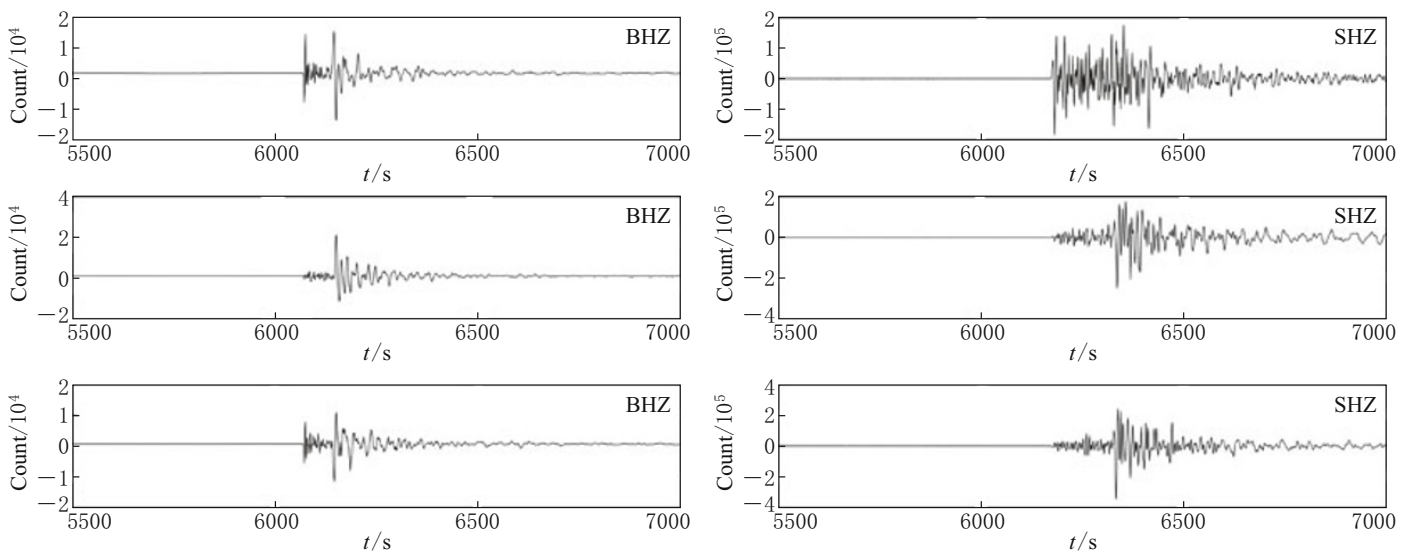

(a)

(b)

Figure 4 (a) The seismic records from YUS station on May 4, 2010. The focal depth of the earthquake is $8 \mathrm{~km}$ with $M_{\mathrm{L}} 1.9$. (b) The seismic records from L6304 station on April 25, 2010. The focal depth of the earthquake is $7.0 \mathrm{~km}$ with $M_{\mathrm{L}} 2.1$. BHZ and SHZ represent instrument record channel.

The $P$ axis of the foreshock, occurred at 05:39 on 14 April 2010, is horizontally at $\operatorname{ENE~}\left(73^{\circ}\right)$, and the $P$ axes of $M_{\mathrm{S}} 7.1$ mainshock and $M_{\mathrm{S}} 6.3$ aftershock are horizontally near $\operatorname{ENE}\left(83^{\circ}\right.$ and $\left.253^{\circ}\right)$. So it can be concluded that the horizontal component direction of principal compressive stress is near ENE before Yushu mainshock. Based on the calculation of focal mechanisms for some moderate and small aftershocks after the mainshock, the $P$ axes of these aftershocks are horizontally near NE or NNE. These moderate aftershocks are spatially near the mainshock. So we can rule out the cause of spatial difference. According to the focal mechanisms of the foreshock and the mainshock, it can be concluded that the original direction of stress is ENE. We concluded that the reason for these differences was that the stress-filed was adjusted after the mainshock and $M_{\mathrm{S}} 6.3$ aftershock on April 14, in fault zone, and the direction of principal compressive stress was changed. The direction of polarization of fast shear-wave in YUS and the directions of $P$ axes of mainshock and $M_{\mathrm{S}} 6.3$ aftershock indicated the direction of local principal compressive before the two earthquake occurred. The direction of polarization in L6304 is consistent with the $P$ axes of $M_{\mathrm{S}} 5.3$ and $M_{\mathrm{S}} 5.7$ aftershocks which occurred later. Thus, all these suggested that the principal compressive stress was adjusted.

In addition, the time span of the waveforms records used in shear-wave splitting in YUS station is April 13-15, 2010. The time span is near the occurrence time of mainshock and $M_{\mathrm{S}} 6.3$ aftershock. However, L6304 station has no record before April 20 when temporary seismic stations have been installed. Temporary stations records are available after April 20, and this time span is consistent with the time of the stress-filed adjustment, therefore the parameters of shear-wave splitting in L6304 station indicated well the local principal compressive after the stress adjustment.

\section{Conclusions}

1) The locations of the mainshock $\left(96.59^{\circ} \mathrm{E}\right.$, $33.13^{\circ} \mathrm{N}, 10.22 \mathrm{~km}$ ) and more than 600 aftershocks were obtained using the double difference algorithm. Most aftershocks distribute in the upper crust, and the average focal depth is about $12.97 \mathrm{~km}$. There are about $95 \%$ aftershocks at depths of $0-20 \mathrm{~km}$ in the crust. The epicentral distribution shows that the length of the aftershock belt is $120 \mathrm{~km}$, and its direction is oriented to WNW-ESE.

2) The focal mechanisms of the mainshock and three strong aftershocks with $M_{\mathrm{S}}>5.0$ were estimated by jointly using far-field velocity waveforms from GSN and Qinghai Seismic Network. According to the relocation, it can be concluded that plane $\left(125^{\circ}, 70^{\circ},-5^{\circ}\right)$ of the mainshock was causative fault plane. The mainshock of Yushu earthquake is left-laterally strike-slip.

3) Through analysis of the parameters of shearwave splitting at stations YUS and L6304, it can be found that the directions of polarization of fast shearwave in the two stations are different. It is near NE at YUS and near NNE at L6304. We concluded that the reason for the difference could be that the stress-field was adjusted around fault zone after the mainshock and the $M_{\mathrm{S}} 6.3$ aftershock on April 14. The direction of principal compressive stress was changed. The time span of the waveforms records which were used in shear-wave 

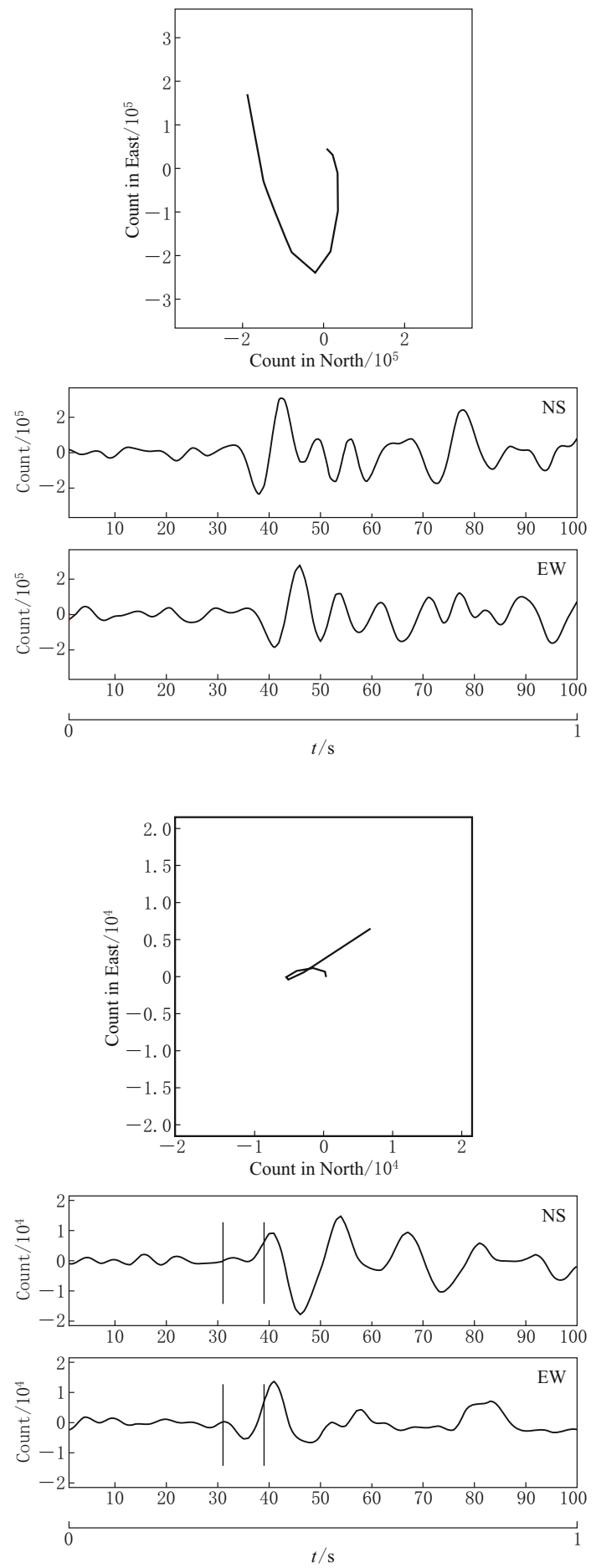

(b)

Figure 5 Example of shear-wave splitting analysis. (a) Shear-wave splitting analysis in L6304 station. The left top picture is particle motion of shear-wave. The left-lower is the record of shear-wave in NS and EW components. The upper-right is particle motion after corrections of time-delay. (b) Shear-wave splitting analysis in YUS station, the detail is the same as that in (a).
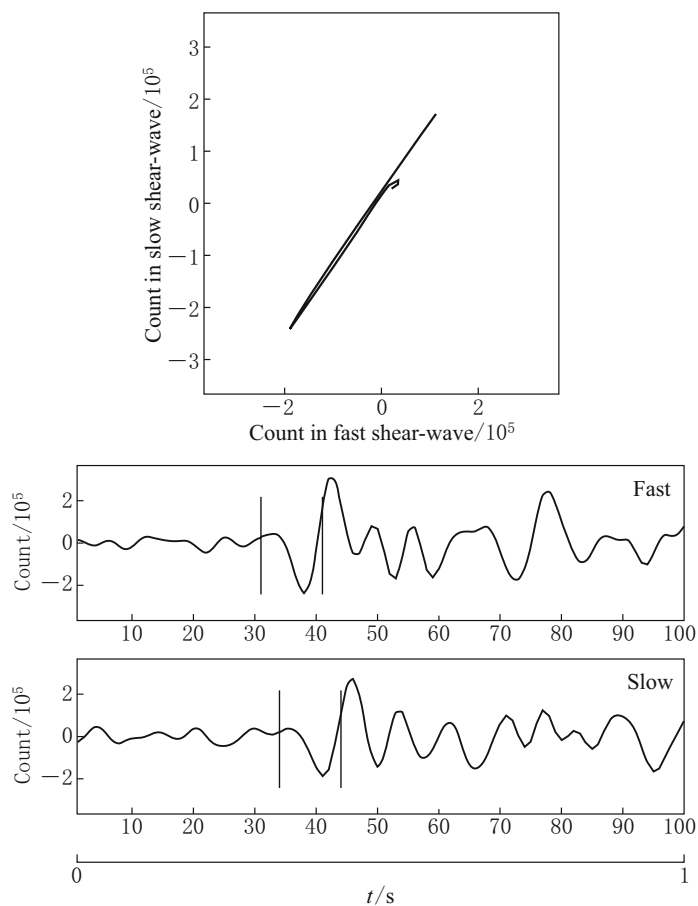

(a)
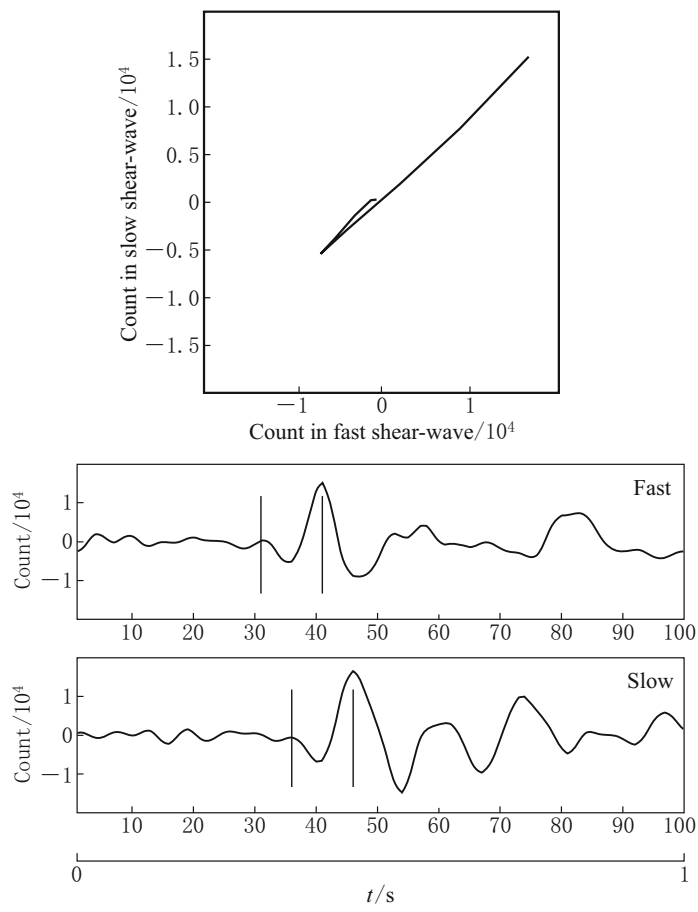


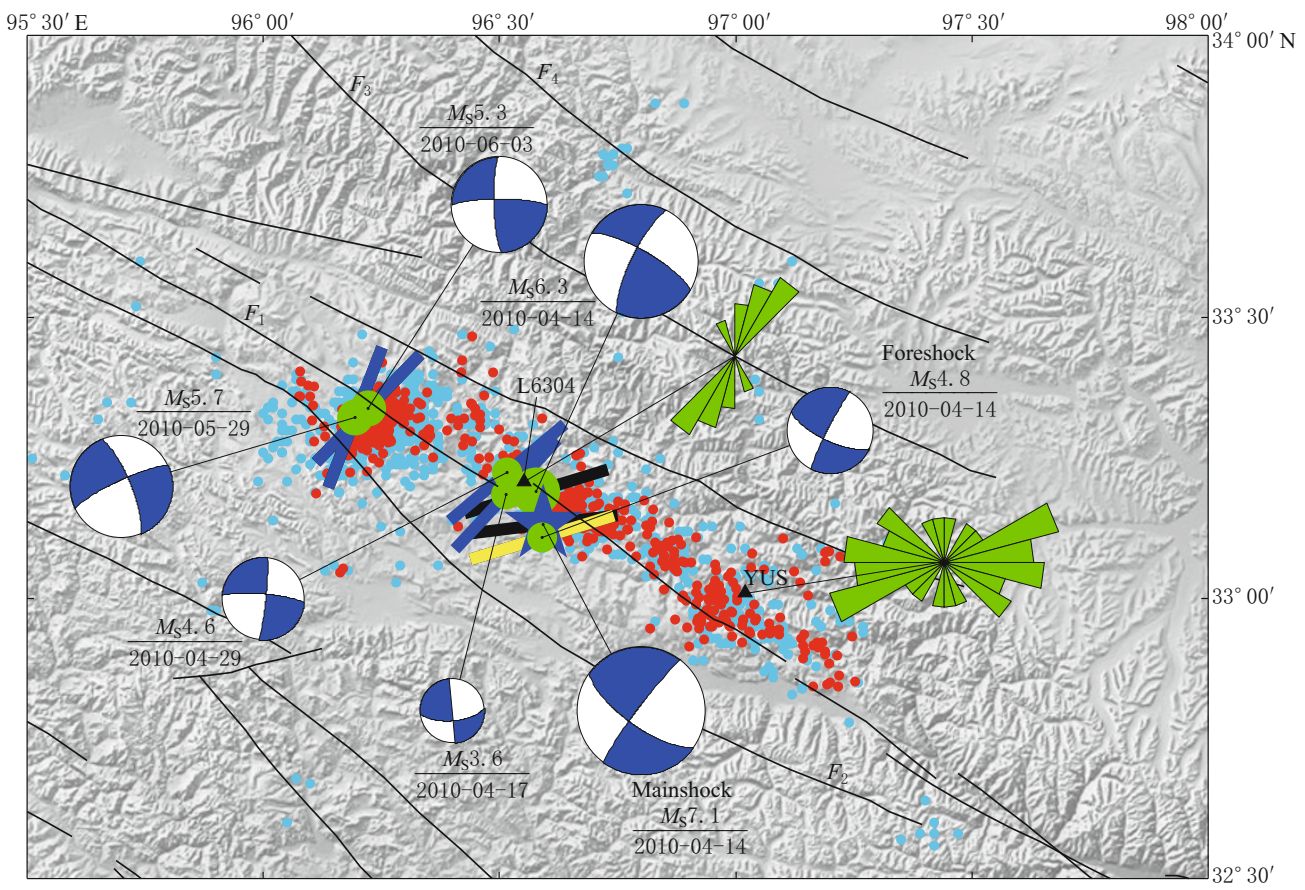

Figure 6 Equal-area projects of fast shear-wave polarizations at YUS and L6304. Focal mechanisms and epicentral distribution are the same as those in Figure 1. The yellow bar represents the $P$ axis of foreshock. The black bars represent the $P$ axes of mainshock and $M_{\mathrm{S}} 6.3$ aftershock. The blue bars represent the $P$ axes of aftershocks which occurred after April 17, 2010.

splitting at YUS is April 13-15, 2010, and the beginning date of L6304 is after April 20. So the direction of polarization of fast shear-wave at YUS and the directions of $P$ axes of mainshock and $M_{\mathrm{S}} 6.3$ aftershock (occurred on April 20) indicated the direction of local principal compressive before the two earthquakes occurred. The direction of polarization at L6304 and $P$ axes of $M_{\mathrm{S}} 5.3$ and $M_{\mathrm{S}} 5.7$ (occurred on May 29 and June 3 ) aftershocks indicated the direction of principal compressive after the two early earthquakes.

Acknowledgements We are grateful to Dr. F Waldhauser for providing HypoDD relocation programs and Dr. Herrmann R B for providing CPS programs. We thank Data Backup Center for China Seismograph Network for providing waveforms. This study was financially supported by basic research project of Institute of Earthquake Science of China Earthquake Science (No. 2009-21) and National Natural Science Foundation of China (No. 41040034).

\section{References}

Crampin S (1994). The fracture criticality of crustal rocks. Geophys J Int 118: 428-438.

Crampin S (1999). Calculable fluid-rock interactions. J Geol
Soc 156: 501-514.

Crampin S and Chastin S (2003). A review of shear wave splitting in the crack-critical crust. Geophys J Int 155: 221-240.

Crampin S and Peacock S (2005). A review of shearwave splitting in the compliant crack critical anisotropic Earth. Wave Motion 41: 59-77.

Gao Y and Crampin S (2004). Observations of stress relaxation before earthquakes. Geophys J Int 157(2): 578582 .

Gao Y and Crampin S (2006). A further stressforecast earthquake (with hindsight), where migration of source earthquakes causes anomalies in shear-wave polarizations. Tectonophysics 426(3/4): 253-262.

Gao Y and Wu J (2008). Compressive stress field in the crust deduced from shear-wave anisotropy: An example in capital area of China. Chinese Science Bulletin 53(18): 2 840-2 848.

Gao Y and Zheng S H (1995). Cross correlation function analysis of shear wave splitting method and example of its application. Journal of Earthquake Prediction Research 4(2): 224-237.

Gao Y, Shi Y L and Liang W (2008). Systematic analysis method of shear-wave splitting SAM (2007): Software system. Earthquake Research in China 24(4): 345-353 (in Chinese with English abstract).

Gao Y, Wang P D, Zheng S H, Wang M, Chen Y T and 
Zhou H L (1998). Temporal changes in shear-wave splitting at an isolated swarm of small earthquakes in 1992 near Dongfang, Hainan Island, southern China. Geophys $J$ Int 135(1): 102-112.

Gao Y, Zheng S and Sun Y (1995). Crack-induced anisotropy in the crust from shear wave splitting observed in Tangshan region, North China. Acta Seismologica Sinica 8(3): 351-363.

Herrmann R (2009). Computer programs in seismology. Version 3.30. www.eas.slu.edu/People/RBHerrmann/CPS/ CPS330.heml.

Liu C, Xu L S and Chen Y T (2010). Quick moment tensor solution for 14 April 2010 Yushu, Qinghai, earthquake. Acta Seismologica Sinica 32(3): 366-368.

Shi Y T, Gao Y, Wu J and Su Y J (2009). Crustal seismic anisotropy in Yunnan, southwestern China. J Seism 13(2): 287-299.

Waldhauser F and Ellsworth L W (2000). A doubledifference earthquake location algorithm: Method and application to the northern Hayward Fault. Bull Seismol Soc Am 90(6): 1 353-1 368.

Wu J, Gao Y, Chen Y T and Huang J (2007). Seismic anisotropy in crust in northwestern capital area of China. Chinese J Geophys 50(1): 209-220 (in Chinese with English abstract).

Yang Z X and Chen Y T (2004). Relocation of the 1998 Zhangbei-Shangyi earthquake sequence using the double difference earthquake location algorithm. Acta Seismologica Sinica 17(2): 125-130.

Zhao B and Gao Y (2010). Crustal share-wave splitting re- search and the effects of earthquake location error on the analyzing results. Earthquake 30(1): 115-124 (in Chinese with English abstract).

Zhao B, Gao Y, Shi Y, Jin H and Sun J (2011b). Shear wave splitting in crust in the intersection zone of ZhangjiakouBohai seismic belt and Shanxi seismic belt. Chinese $J$ Geophys 54(6): 1 517-1 527 (in Chinese with English abstract).

Zhao B, Shi Y T and Gao Y (2011a). Relocations of aftershocks of Wenchuan $M_{\mathrm{S}} 8.0$ earthquake and its implication to seismotectonics. Earthquake Science 24: 107-113.

Zhang Z, Teng J, Badal J and Liu E (2009). Construction of regional and local seismic anisotropic structures from wide-angle seismic data: Crustal deformation in the southeast of China. J Seism 13(2): 241-252.

Zheng X, Chen C and Zhang C (2008). Study on temporal variations of shear-wave splitting in the Chiayi area, aftershock zone of 1999 Chichi earthquake, Taiwan. Chinese J Geophys 51(1): 149-157 (in Chinese with English abstract).

Zhu A, Xu X, Diao G, Su J, Feng X, Sun Q and Wang Y (2008). Relocation of the $M_{\mathrm{S}} 8.0$ Wenchuan earthquake sequence in part: Preliminary seismotectonic analysis. Seismology and Geology 30(3): 759-767 (in Chinese with English abstract).

Zhu A, Xu X, Hu P, Zhou Y, Lin Y, Chen G and Gan W (2005). Relocation of small earthquakes in Beijing area and its implication to seismotectonics. Geological Review 51(3): 268-274. 